\title{
Factors Influencing the Number of Buds per Inflorescence in Sweet Pea (Lathyrus odoratus L.)
}

\author{
Takashi Fudano $^{1 *}$, Takahiro Hayashi ${ }^{2}$ and Susumu Yazawa ${ }^{2}$ \\ ${ }^{1}$ Experimental Farm, Graduate School of Agriculture, Kyoto University, Takatsuki 569-1115, Japan \\ ${ }^{2}$ Graduate School of Agriculture, Kyoto University, Kyoto 606-8502, Japan
}

The number of buds per inflorescence fluctuates irregularly in the sweet pea (Lathyrus odoratus L.) winterflowering variety 'Early Pink'. The number of buds per inflorescence and the fluctuation of the number of buds per inflorescence differ remarkably among plants. The number of buds per inflorescence, diameter of flower stalks, dry matter of cut flowers, and diameter of internodes increased, and short cyclic fluctuations in the number of buds per inflorescence were suppressed as the frequency of removing immature inflorescences increased. Using a moving average, the fluctuation of the number of buds per inflorescence was found to be a combination of two periodic fluctuations in 26 of 36 plants. The 2-3, 4-6, 8-12, and more than 15 node periodic fluctuations were found in 10, 15, 11, and 16 plants, respectively. From these results, the factors that cause the number of buds per inflorescence to fluctuate are discussed.

Key Words: deconstruction of fluctuation, moving average, number of buds per inflorescence, periodic fluctuation, sweet pea.

\section{Introduction}

Sweet pea (Lathyrus odoratus L.) is an important cut flower crop. Several factors lead to a reduction in the number and quality of flowers available for cutting. Flower bud abscission occurs when cloudy and rainy weather persists over several days in winter. Excessive irrigation and fertilization encourage plant vigor, which results in flower bud abscission and abortion. These factors lead to a reduction in the number of flowers and deterioration in the quality of flowers available for cutting. When a plant loses vigor because of overharvesting, it results in a decrease in the number of buds per inflorescence and loss of flower quality. Cut flowers bearing four to five buds must be continuously harvested for several months in commercial cut flower production. Plants subjected to such stresses take time to recover; a month is usually needed before good quality flowers can be harvested again from the plant; therefore, it is very important for cut flower production to keep plant vigor constant (Inoue et al., 1989).

Even if the data seem to fluctuate randomly, in many cases they are actually determined by an immanency

Received; August 23, 2008. Accepted; April 3, 2009.

* Corresponding author (E-mail: fudano@kais.kyoto-u.ac.jp). rhythm, a seasonal rhythm, residual error, etc. (Griffiths et al., 2003); therefore, if an irregular fluctuation can be broken down into periodic fluctuations, the periodicity latent in the irregular fluctuations can be clarified. A useful tool for discovering periodicity is the moving average, which is an important and fundamental tool used to smooth out short cyclic fluctuations, thus highlighting longer-term trends or cycles hidden in the data series.

It is known that plant growth is not constant and changes periodically. These periodic fluctuations include diurnal and seasonal rhythms that are influenced by external conditions and nutation and internal rhythms that are not influenced by external conditions (Öpik and Rolfe, 2005). In sweet pea, the number of buds per inflorescence is strongly influenced by plant vigor, which also fluctuates irregularly. The fluctuation in the number of buds per inflorescence might be expressed by a combination of simple periodic fluctuations. In this study, we analyzed the periodic fluctuations latent in the irregular fluctuation of the number of buds per inflorescence using moving averages. The factors causing fluctuation in the number of buds per inflorescence are discussed. 


\section{Materials and Methods}

Fluctuation in the number of buds per inflorescence

Experiments were carried out on the winter-flowering sweet pea variety 'Early Pink'. Seeds obtained from a commercial nursery were soaked in distilled water for about $6 \mathrm{~h}$. Pre-germinated seeds were stored at $1{ }^{\circ} \mathrm{C}$ for 15 days. Three seeds were sown per planting hole in rows. The inter- and intra-row spaces were $30 \mathrm{~cm}$. All plants were grown in a plastic house maintained at a minimum temperature of $5^{\circ} \mathrm{C}$ under natural day-length on September 1, 1996. Plants with inferior growth were thinned out leaving two plants per planting hole. Liquid fertilizer $(\mathrm{N}: \mathrm{P}: \mathrm{K}=14: 8: 16)$ with nitrogen concentration diluted to $200 \mathrm{ppm}$ was applied at about $7 \mathrm{~L} \cdot \mathrm{m}^{-2}$ every week from November onwards. All axillary buds and tendrils were removed at the earliest possible stage of growth. The vine was trained horizontally. In order to maintain plant vigor, the first and second inflorescences were removed just after budding. Inflorescences were harvested when the three basal florets fully opened. The number of buds per inflorescence was counted for all inflorescences harvested from 36 plants. Fluctuations in the number of buds per inflorescence were calculated with coefficients of variation.

\section{Effects of immature inflorescence removal treatment on the number of buds per inflorescence}

When plants that flower at lower nodes continue to be grown and harvested, the vigor of the plant may decline quickly. In commercial cut flower production, plant vigor is maintained by removing immature inflorescences (Inoue, 2007); therefore, the effect of immature inflorescence removal treatment on the number of buds per inflorescence was investigated. Seeds obtained from a commercial nursery were soaked in distilled water for about $6 \mathrm{~h}$. Pre-germinated seeds were stored for 2 weeks at $1{ }^{\circ} \mathrm{C}$. Three seeds were sown per planting hole in containers $(90 \mathrm{~cm} \times 180 \mathrm{~cm} \times 30 \mathrm{~cm})$ on October 1, 1995. The inter- and intra-row spaces were 50 and $20 \mathrm{~cm}$, respectively. The containers were placed in a plastic house maintained at a minimum temperature of $5^{\circ} \mathrm{C}$ under natural day-length. Plants with inferior growth were thinned out, leaving two plants per hole. Liquid fertilizer $(\mathrm{N}: \mathrm{P}: \mathrm{K}=10: 5: 8)$ with nitrogen concentration diluted to $300 \mathrm{ppm}$ was applied at $30 \mathrm{~L}$ per container every week from November onwards. All axillary buds and tendrils were removed in the earliest possible stage of growth. The vine was trained horizontally. In order to maintain plant vigor, the first and second inflorescences were removed just after budding.

Immature inflorescences were removed as follows: no removal (control); allowing three inflorescences to bear flowers and removing the immature fourth (treatment 1); allowing two inflorescences to bear flowers and removing the immature third (treatment 2); leaving one to bear flowers and removing the next immature one (treatment 3); leaving one to bear flowers and removing the next two immature ones (treatment 4); and leaving one to bear and removing the next three immature ones (treatment 5) (Table 1). Inflorescences were harvested when the three basal florets fully opened. The number of buds per inflorescence, length and diameter of flower stalks, dry matter of cut flowers, number of cut flowers per plant, length and diameter of internodes, number of nodes per plant, and length of leaflets were recorded. Measurements were made for ten plants per experimental unit.

\section{Determination of fluctuations in the number of buds per inflorescence using moving averages}

The number of buds per inflorescence was analyzed using autocorrelation and moving average (Ohmura, 1993). The process by which fluctuation in the number of buds per inflorescence of 96P03 (individual number) is deconstructed is shown as an example (Fig. 1). The means and coefficients of variation for the number of buds per inflorescence of $96 \mathrm{P} 03$ were 6.9 and 14.7, respectively (Fig. 1A). First, the autocorrelation coefficient for the number of buds per inflorescence was calculated. This autocorrelation coefficient is plotted in Figure 1B. The autocorrelation coefficient when shifting a two node position was high and when shifting 6 and 8 node positions, which are a multiple of 2 , was larger than when shifting 1, 3, 5, and 9 node positions; therefore, the periodic fluctuation of two nodes may be latent in the fluctuation in the number of buds per inflorescence. By taking the two-point moving average of the number of buds per inflorescence, the two node periodic

Table 1. Immature inflorescence removal treatment in sweet pea 'Early Pink'.

\begin{tabular}{lccccccccc}
\hline \hline \multirow{2}{*}{ Treatment } & \multicolumn{10}{c}{ Node position } \\
\cline { 2 - 9 } & $\mathrm{n}$ & $\mathrm{n}+1$ & $\mathrm{n}+2$ & $\mathrm{n}+3$ & $\mathrm{n}+4$ & $\mathrm{n}+5$ & $\mathrm{n}+6$ & $\mathrm{n}+7$ & $\ldots$ \\
\hline Control & $\mathrm{O}^{2}$ & $\mathrm{O}$ & $\mathrm{O}$ & $\mathrm{O}$ & $\mathrm{O}$ & $\mathrm{O}$ & $\mathrm{O}$ & $\mathrm{O}$ & $\ldots$ \\
Treatment 1 & $\mathrm{O}$ & $\mathrm{O}$ & $\mathrm{O}$ & $\times$ & $\mathrm{O}$ & $\mathrm{O}$ & $\mathrm{O}$ & $\times$ & $\ldots$ \\
Treatment 2 & $\mathrm{O}$ & $\mathrm{O}$ & $\times$ & $\mathrm{O}$ & $\mathrm{O}$ & $\times$ & $\mathrm{O}$ & $\mathrm{O}$ & $\ldots$ \\
Treatment 3 & $\mathrm{O}$ & $\times$ & $\mathrm{O}$ & $\times$ & $\mathrm{O}$ & $\times$ & $\mathrm{O}$ & $\times$ & $\ldots$ \\
Treatment 4 & $\mathrm{O}$ & $\times$ & $\times$ & $\mathrm{O}$ & $\times$ & $\times$ & $\mathrm{O}$ & $\times$ & $\ldots$ \\
Treatment 5 & $\mathrm{O}$ & $\times$ & $\times$ & $\times$ & $\mathrm{O}$ & $\times$ & $\times$ & $\times$ & $\ldots$ \\
\hline
\end{tabular}

${ }^{\mathrm{z}} \mathrm{O}$ : no treatment, $\times$ : inflorescence removal treatment 
fluctuation can be removed. When the two node periodic fluctuation was removed, an about nine node periodic fluctuation appeared (Fig. 1C). Thus, the fluctuation of the number of buds per inflorescence was deconstructed into two periodic fluctuations: the two node periodic fluctuation and the nine node periodic fluctuation. This method was used to identify latent periodic fluctuations from the number of buds per inflorescence in the other 35 plants.
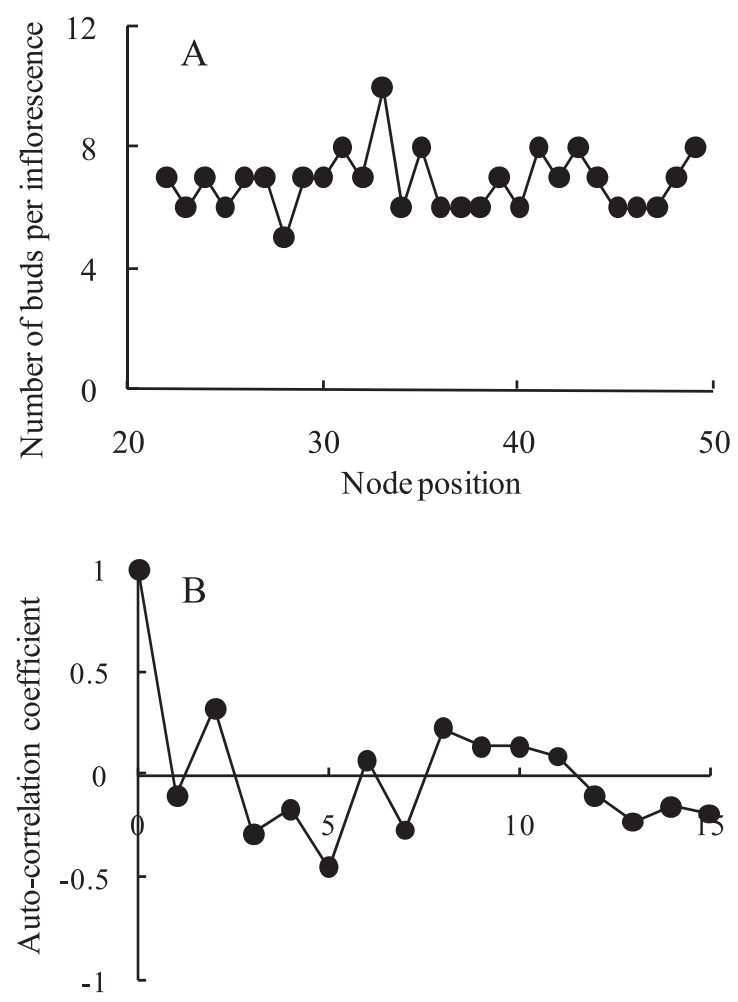

Node shift

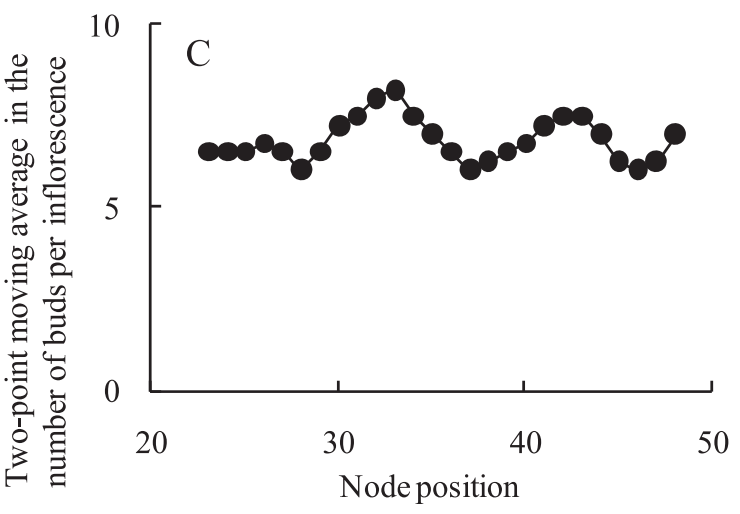

Fig. 1. The process by which fluctuation in the number of buds per inflorescence is deconstructed in sweet pea 'Early Pink' (individual number 96P03). A: Fluctuation in the number of buds per inflorescence. B: Correlogram of the number of buds per inflorescence. C: Two-point moving average in the number of buds per inflorescence.

\section{Results and Discussion}

Fluctuation in the number of buds per inflorescence

A total of 914 inflorescences bloomed from November 1996 to April 1997. All inflorescences were harvested and the number of buds per inflorescence was counted. The means and coefficients of variation in the number of buds per inflorescence were 5.0-12.9 and 7.1\%$33.9 \%$, respectively (Fig. 2 ). Because the fluctuation in the number of buds per inflorescence differed remarkably among plants, it was expressed as coefficient of variation for every plant in this study. Factors that cause fluctuation of the number of buds per inflorescence may include temperature, solar radiation, irrigation, fertilization, training of the vine, distribution of dry matter, and genetic factors. Plant growth is controlled by disbudding and management of fertilization, irrigation, and temperature on the basis of plant form (so called tenbanakankaku), the color of the leaf, and the cut flower length (Inoue et al., 1989). A tenbana-kankaku means the distance from the shoot apex to the uppermost fully opened floret. When the tenbana-kankaku of a plant is high, it is assumed that the plant has vigorous succulent growth, and when it is low or negative; it is assumed that the plant is losing vigor. Although monitoring the tenbana-kankaku, color of the leaf and cut flower length is effective in maintaining plant vigor, it may be difficult to cope with short cyclic fluctuations in the number of buds per inflorescence, as shown in Figure 1A, based on these measurements alone.

\section{Effects of immature inflorescence removal treatment on} the number of buds per inflorescence

Removal of immature inflorescences significantly affected the number of buds per inflorescence, diameter of flower stalks, dry matter of cut flowers, number of cut flowers per plant, and diameter of internodes (Table 2). The number of buds per inflorescence, diameter of flower stalks, dry matter of cut flowers, and diameter of internodes increased with the frequency of the removal of immature inflorescences. Removal of

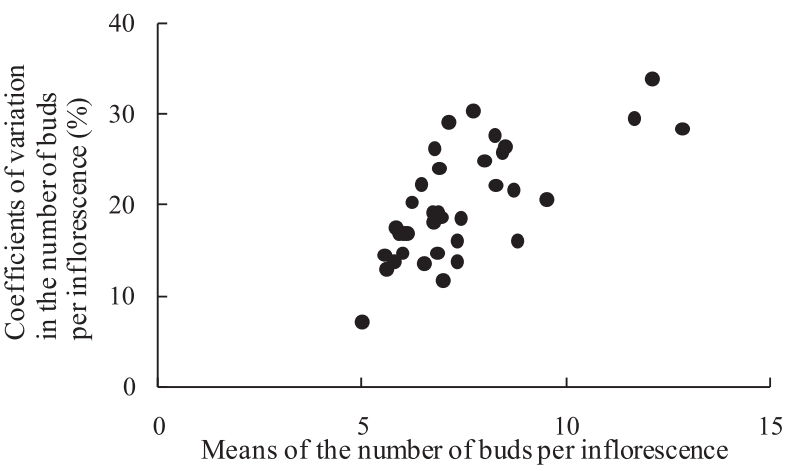

Fig. 2. Plot of means and coefficients of variation in the number of buds per inflorescence among plants $(n=36)$ in sweet pea 'Early Pink'. 
immature inflorescences did not affect the length of the flower stalk, internode, or leaflet, and the number of nodes. Fluctuation in the number of buds per inflorescence in four representative plants chosen for each different treatment is shown in Figure 3. The number of buds per inflorescence fluctuated every several nodes in the control (Fig. 3A) but the fluctuation pattern in the number of buds per inflorescence at the highest frequency of removal of immature inflorescences showed only one peak during the harvesting period
(Fig. 3F). Short cyclic fluctuations in the number of buds per inflorescence were suppressed as the frequency of removing immature inflorescences increased.

Marcelis (1993) reported that the number of sink organs per plant influences the growth of both vegetative and reproductive organs. There is an inverse relationship between the number of reproductive organs and their size (Peters et al., 1988). If the number of reproductive organs is restricted, the size of each reproductive organ increases by reducing competition for photosynthate

Table 2. Effect of immature inflorescence removal treatment on nine characteristics of sweet pea 'Early Pink'.

\begin{tabular}{lccccccccc}
\hline \hline Treatment & $\begin{array}{l}\text { Number of } \\
\text { buds per } \\
\text { inflorescence }\end{array}$ & $\begin{array}{c}\text { Length of } \\
\text { flower stalk } \\
(\mathrm{cm})\end{array}$ & $\begin{array}{c}\text { Diameter of } \\
\text { flower stalk } \\
(\mathrm{cm})\end{array}$ & $\begin{array}{c}\text { Dry matter of } \\
\text { cut flower } \\
(\mathrm{g})\end{array}$ & $\begin{array}{l}\text { Number of } \\
\text { cut flowers } \\
\text { per plant }\end{array}$ & $\begin{array}{c}\text { Length of } \\
\text { internode } \\
(\mathrm{cm})\end{array}$ & $\begin{array}{l}\text { Diameter of } \\
\text { internode } \\
(\mathrm{cm})\end{array}$ & $\begin{array}{l}\text { Number of } \\
\text { nodes }\end{array}$ & $\begin{array}{l}\text { Length of } \\
\text { leaflet } \\
(\mathrm{cm})\end{array}$ \\
\hline Control & $6.7 \mathrm{~b}^{2}$ & $65.0 \mathrm{a}$ & $0.46 \mathrm{~b}$ & $1.25 \mathrm{~b}$ & $15.7 \mathrm{a}$ & $9.6 \mathrm{a}$ & $0.64 \mathrm{~b}$ & $31.3 \mathrm{a}$ & $8.8 \mathrm{a}$ \\
Treatment 1 & $6.6 \mathrm{~b}$ & $61.8 \mathrm{a}$ & $0.47 \mathrm{~b}$ & $1.28 \mathrm{ab}$ & $12.9 \mathrm{a}$ & $9.4 \mathrm{a}$ & $0.65 \mathrm{~b}$ & $30.6 \mathrm{a}$ & $9.0 \mathrm{a}$ \\
Treatment 2 & $6.0 \mathrm{~b}$ & $61.6 \mathrm{a}$ & $0.47 \mathrm{ab}$ & $1.26 \mathrm{~b}$ & $10.5 \mathrm{~b}$ & $10.8 \mathrm{a}$ & $0.66 \mathrm{~b}$ & $31.2 \mathrm{a}$ & $9.5 \mathrm{a}$ \\
Treatment 3 & $7.4 \mathrm{~b}$ & $58.4 \mathrm{a}$ & $0.48 \mathrm{ab}$ & $1.24 \mathrm{~b}$ & $7.8 \mathrm{c}$ & $10.1 \mathrm{a}$ & $0.65 \mathrm{~b}$ & $32.6 \mathrm{a}$ & $8.9 \mathrm{a}$ \\
Treatment 4 & $7.4 \mathrm{ab}$ & $61.1 \mathrm{a}$ & $0.51 \mathrm{a}$ & $1.38 \mathrm{ab}$ & $5.5 \mathrm{~d}$ & $9.3 \mathrm{a}$ & $0.73 \mathrm{ab}$ & $31.1 \mathrm{a}$ & $9.1 \mathrm{a}$ \\
Treatment 5 & $9.0 \mathrm{a}$ & $60.6 \mathrm{a}$ & $0.51 \mathrm{a}$ & $1.45 \mathrm{a}$ & $4.8 \mathrm{e}$ & $10.2 \mathrm{a}$ & $0.78 \mathrm{a}$ & $31.0 \mathrm{a}$ & $9.6 \mathrm{a}$ \\
\hline
\end{tabular}

${ }^{z}$ Values followed by the same letter within a column were not significantly different at $P<0.05$ by Tukey's test.
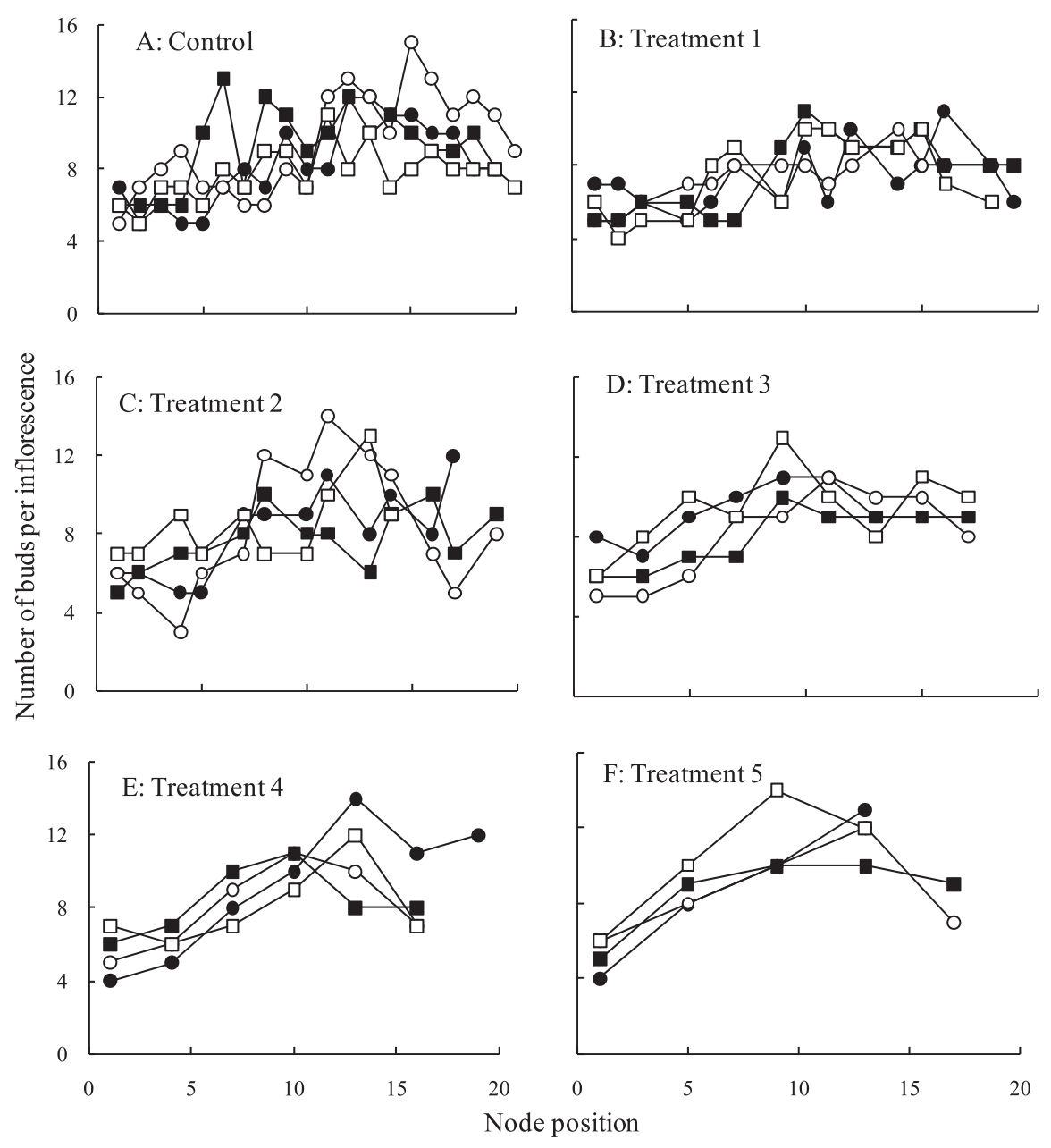

Fig. 3. Effect of immature inflorescence removal treatment (see Table 1) on fluctuations in the number of buds per inflorescence in sweet pea 'Early Pink'. Fluctuation in the number of buds per inflorescence of four representative plants in each treatment is shown. 
among organs. In this study, the number of buds in the inflorescences increased by restricting the number of inflorescences per plant. Our previous study indicated that the amount of ${ }^{13} \mathrm{C}$ distribution to the apical portion and the inflorescence increased by removing buds from other inflorescences (Fudano et al., 2001). The increase in the number of buds per inflorescence may result from the increased amount of photosynthate distributed to the apical portion. In addition, short cyclic fluctuations in the number of buds per inflorescence were suppressed by restricting the number of inflorescences per plant. These results suggest that one of the factors that cause fluctuation in the number of buds per inflorescence is competition for photosynthate.

\section{Determination of fluctuation in the number of buds per inflorescence using moving average}

Fluctuation in the number of buds per inflorescence could be deconstructed into two periodic fluctuations using the moving average in 26 of 36 plants. For 10 of these 36 plants, this could not be done, because there was no peak on the correlogram or because no periodic fluctuation was discovered using the moving average. The period of fluctuation observed by a moving average was $2-3,4-6,8-12$, and more than 15 nodes. There were $6,4,4,5$, and 7 plants whose fluctuation in the number of buds per inflorescence could be expressed with the combination of 2-3 node and 4-6 node periodic fluctuation, 2-3 node and more than 15 node periodic fluctuation, 4-6 node and 8-12 node periodic fluctuation, 4-6 node and more than 15 node periodic fluctuation, and 8-12 node and more than 15 node periodic fluctuation, respectively (Table 3). Accordingly, 2-3, 4$6,8-12$, and more than 15 node periodic fluctuation were found in $10,15,11$, and 16 plants, respectively. The more than 15 node periodic fluctuation predominated. The fluctuation in the number of buds per inflorescence of $96 \mathrm{P} 43$ (individual number), in which the more than 15 node periodic fluctuation was latent, is shown as an example (Fig. 4A). By removing the four node periodic fluctuation, a more than 15 node periodic fluctuation appeared (Fig. 4B). The more than 15 node periodic fluctuation occurred throughout the harvesting time. As for the flowering period, it is desirable to maintain the temperature in the greenhouse at $\leq 20-23^{\circ} \mathrm{C}$ during the daytime and $5^{\circ} \mathrm{C}$ at night (Inoue et al., 1989;

Table 3. The number of plants whose fluctuation in the number of buds per inflorescence could be expressed with the combination of two latent periodic fluctuations in 26 of 36 plants in sweet pea 'Early Pink'.

\begin{tabular}{lcccc}
\hline \hline Length of period & $\begin{array}{c}2 \text { to } 3 \\
\text { node }\end{array}$ & $\begin{array}{c}4 \text { to } 6 \\
\text { node }\end{array}$ & $\begin{array}{c}8 \text { to } 12 \\
\text { node }\end{array}$ & $\begin{array}{c}\text { More than } \\
15 \text { node }\end{array}$ \\
\hline 2 to 3 node & - & 6 & 0 & 4 \\
4 to 6 node & & - & 4 & 5 \\
8 to 12 node & & & - & 7 \\
More than 15 node & & & & - \\
\hline
\end{tabular}

Inoue and Higuchi, 1988). The periodic fluctuation of the whole harvesting time decreased, corresponding to the rise of temperature from the middle of March onward (Fig. 4C). In addition, from March onward, when day length and solar radiation increase, the bloom interval decreases and the plant loses vigor due to overharvesting; therefore, periodic fluctuation throughout the harvesting time may be induced by environmental changes or ageing and senescence of the plant.
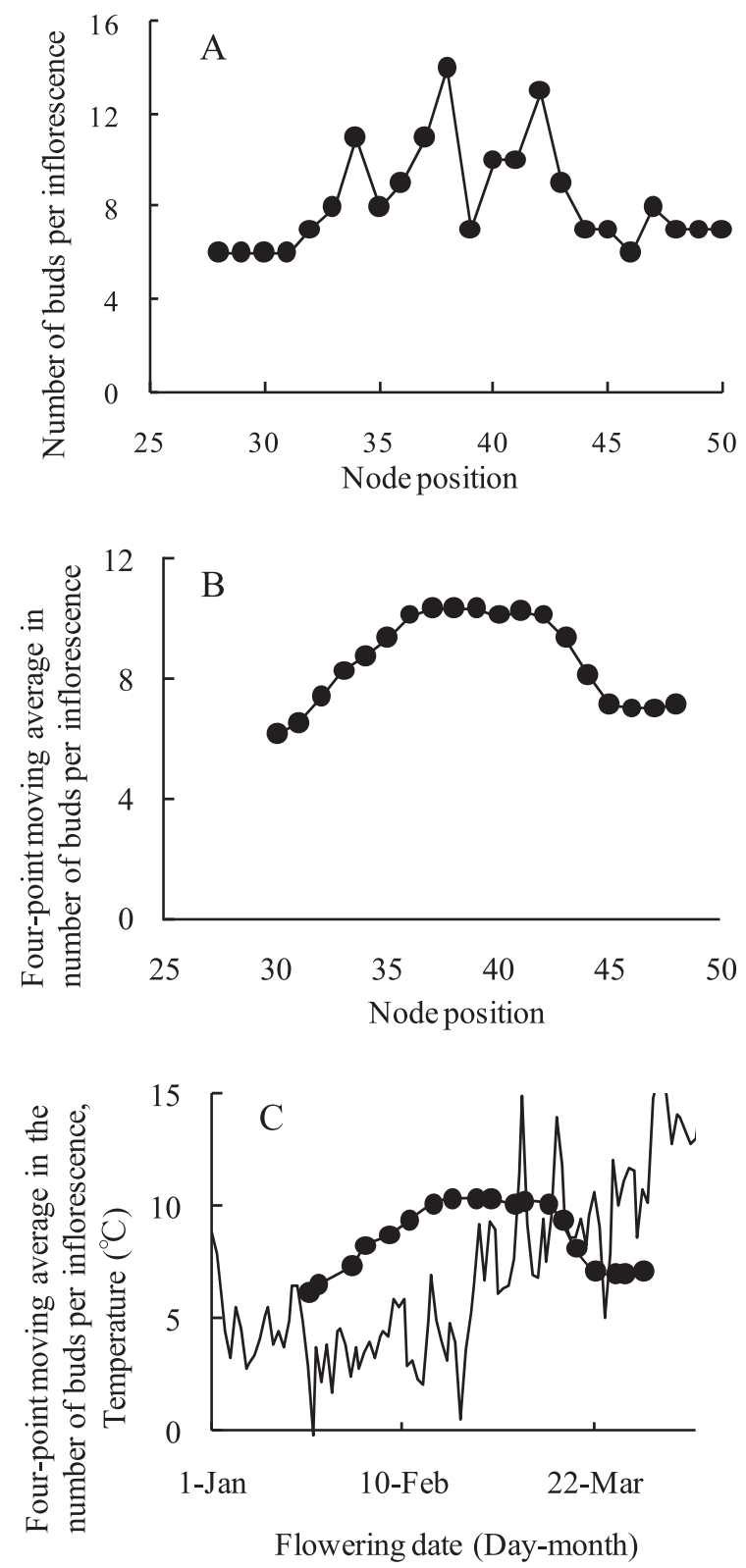

Fig. 4. The fluctuation in the number of buds per inflorescence in sweet pea 'Early Pink' (individual number 96P43) in which the more than 15 node periodic fluctuation was latent. A: Fluctuation in the number of buds per inflorescence. B: Four-point moving average in the number of buds per inflorescence. C: Change of temperature and the four-point moving average in the number of buds per inflorescence. The solid line is average temperature, - is four-point moving average in the number of buds per inflorescence. 


\section{Conclusion}

From the results of this study, it became clear that periodic fluctuations were latent in the irregular fluctuation in the number of buds per inflorescence of some plants. Competition for photosynthate and environmental changes or ageing and senescence of the plant can be considered as factors causing fluctuation in the number of buds per inflorescence. Although it is difficult to control these factors, it is possible to control competition for photosynthate. Management practices, which reduce competition for photosynthate, will be effective in suppressing the fluctuation in the number of buds per inflorescence.

\section{Literature Cited}

Fudano, T., T. Hayashi and S. Yazawa. 2001. Partitioning of ${ }^{13} \mathrm{C}$ photosynthate in sweet pea (Lathyrus odoratus L.) plants during the flowering period. J. Japan. Soc. Hort. Sci. 70: 102107 (In Japanese with English abstract).

Griffiths, D., W. D. Stirling and K. L. Weldon. 2003. Henkawosaguru-Zikeiretu (In Japanese). p. 67-103. In: K.
Tsuzaki (ed.). (Translation). De-takaramanabutoukeigaku. Medical Science International, Tokyo.

Inoue, T. 2007. Sui-topi-wotukurikonasu (In Japanese). Noubunkyou, Tokyo.

Inoue, T. and H. Higuchi. 1988. Effects of air and soil temperature on growth and flowering in sweet pea. Abstr. Japan. Soc. Hort. Sci. Autumn Meet.: 444-445 (In Japanese).

Inoue, T., T. Hasegawa and H. Higuchi. 1989. Relationship between the length of cut flower and leaf area of flowerd node, and so called "Tenbana-kankaku" in sweet pea. J. Japan. Soc. Hort. Sci. 58 (Suppl. 1): 392-393 (In Japanese).

Marcelis, L. F. M. 1993. Simulation of biomass allocation in greenhouse crops. Acta Hort. 328: 49-67.

Ohmura, T. 1993. Torendowokaisekisurutameni (In Japanese). p. 29-79. In: T. Ohmura (ed.). Yosokunohanasi. Nikkagiren, Tokyo.

Öpik, H. and S. Rolfe. 2005. Growth as a quantitative process. p. 161-176. In: H. Öpik and S. Rolfe (eds.). The physiology of flowering plants. Cambridge University Press, Cambridge.

Peters, R. H., S. Cloutier, D. Dube, A. Evens, P. Hastings, H. Kaiser, D. Kohn and B. Sarwer Foner. 1988. The allometry of the weight of fruit on trees and shrubs in Barbados. Oecologia 74: 612-616. 